\title{
Non-Native Herbivores Promote Plant Invasions Away From Mountain Roads in the Andes
}

\author{
Valeria Aschero ( $\nabla$ vaschero@mendoza-conicet.gob.ar) \\ CONICET Mendoza https://orcid.org/0000-0003-3865-4133
}

\section{Agustina Barros}

Argentine Institute of Snow Research Glaciology and Environmental Sciences: Instituto Argentino de Nivologia Glaciologia y Ciencias Ambientales

\section{Lorena Bonjour}

IADIZA CONICET

\section{Ana Mazzolari}

IANIGLA: Instituto Argentino de Nivologia Glaciologia y Ciencias Ambientales

\section{Martín Pérez Sosa}

Facultad de Cs. Agrarias, UnCUYO

\section{Fernanda Cuevas}

IADIZA: Instituto Argentino de Investigaciones de las Zonas Aridas

\section{Agustina Novillo}

IADIZA: Instituto Argentino de Investigaciones de las Zonas Aridas

\section{María Alisa Álvarez}

IADIZA: Instituto Argentino de Investigaciones de las Zonas Aridas

\section{Eduardo Fuentes Lillo}

LIB, Univ. de Concepción ,Chile

\section{Anibal Pauchard}

Universidad de Concepción: Universidad de Concepcion

Jonas Lembrechts

University of Antwerp

\section{Research Article}

Keywords: livestock, aliens, plant invasions, elevational gradient, Andean plant communities

Posted Date: December 1st, 2021

DOl: https://doi.org/10.21203/rs.3.rs-979953/v1

License: (9) This work is licensed under a Creative Commons Attribution 4.0 International License. 

1 Title: Non-native herbivores promote plant invasions away from mountain roads in the Andes

2 Aschero, V. ${ }^{1,2 x}$, Barros A ${ }^{1 x}$, Bonjour L.. ${ }^{3}$, Mazzolari A. ${ }^{1}$, Pérez Sosa M. ${ }^{4}$, Cuevas M.F. ${ }^{3,}$, Novillo,

3 A. ${ }^{8}$, Alvarez M.A. ${ }^{3}$, Fuentes Lillo E. ${ }^{5,9}$, Pauchard A. ${ }^{5,6}$, Lembrechts, J. ${ }^{7}$

$4{ }^{\mathrm{x}} \mathrm{VA}$ and BA contributed equally to this manuscript and wish to be considered joint first authors.

6 1. Instituto Argentino de Nivología, Glaciología y Ciencias Ambientales (IANIGLA),

7 CONICET Mendoza CC330, 5500 Mendoza, Argentina

8 2. Facultad de Ciencias Exactas y Naturales, Universidad Nacional de Cuyo, M5502jMA Mendoza,

9 Argentina

10 3. Instituto Argentino de Investigaciones de las Zonas Áridas, CCT CONICET Mendoza, CC 507, 115500 Mendoza, Argentina

12 4. Facultad de Ciencias Agrarias, Universidad Nacional de Cuyo, Argentina

13 5. Laboratorio de Invasiones Biológicas (LIB), Facultad de Ciencias Forestales, Universidad de 14 Concepción, Concepción, Chile

15 6. Instituto de Ecología y Biodiversidad (IEB), Santiago, Chile

16 7. Research Group PLECO (Plants and Ecosystems), University of Antwerp, Wilrijk, Belgium

17 8. Instituto de Biodiversidad Neotropical, CCT Tucumán - UNT. Cúpulas Horco Molle. Yerba 18 Buena, Tucumán, Argentina.

19 9. School of Education and Social Sciences, Adventist University of Chile, Chillán, Chile

**Corresponding author +54261 5244275, fax +54 261 5244201, e-mails: vaschero@mendozaconicet.gob.ar

23 Running headline: non-native plants in the Arid Andes

24 Word count (introduction through acknowledgments): 3887 


\section{Abstract}

27 While the role of environmental filters, usually described by elevation as proxy, and anthropogenic disturbance as drivers of non-native plant diversity and abundance in mountains have been extensively studied, the impact of herbivores are less explored. Livestock grazing can facilitate the introduction of non-native species by seed dispersal and reduce biotic resistance due to consumption and trampling of native plants, even in the highest protected areas in the Andes. We here explored the effects of elevation, livestock and distance to the road on non-native and native plant distributions. Our results confirm the largely negative relationship of non-native plant richness and cover with elevation, with a peak in richness and cover at low to intermediate elevations. Similarly, we show a strong decline in non-native richness with increasing distance to the road, especially at low elevations, accompanied by a strong negative effect of roads on native species richness. Most importantly, however, we show that the presence of non-native herbivores greatly increases the cover of non-native species away from the roadside, identifying herbivore disturbance as a potential catalyst of non-native plant invasion into natural vegetation of high-Andean protected areas. Our results confirm the often-shown role of disturbance as driver of plant invasions in mountains, yet highlight the interactive effects of disturbance by roads and herbivory: roads funnel non-native species towards higher elevations, while non-native herbivores can promote non-native plant success away from the roadside and into the natural vegetation. Hence, regulating soil and non-native herbivory disturbance is important for minimizing plant invasions at high elevation in the Arid Andes.

Keywords: livestock, aliens, plant invasions, elevational gradient, Andean plant communities.

\section{Introduction}

49 Plant invasions in mountains are an increasing threat to biodiversity conservation as climate changes and anthropogenic disturbance increases (Pauchard et al., 2009; McDougall et al., 2011; Seipel et al., 2012; Petitpierre et al., 2016). There have been recent efforts to assess distribution and abundance of non-native plants in mountain areas around the world including in Europe (Alexander et al., 2009), Asia (McDougall et al., 2011), North America (Parks et al., 2005), Australia (McDougall et al., 2005), New Zealand (Jesson et al., 2000), and the Andes in South America 
56 Fuentes-Lillo \& Pauchard, 2019). Most of these studies highlighted that disturbance and environmental filtering due to increasing abiotic stress with elevation both play a critical role controlling non-native plant diversity in mountains (Alexander et al., 2011; Alexander et al., 2016).

Roads are a common disturbance factor in mountains and are known to facilitate the expansion of non-native plants to higher elevations (Alexander et al., 2011) and lead to biotic homogenization (Haider et al., 2020). Roads can affect various local abiotic and biotic factors including soil structure and chemistry (Mullerova et al., 2011), removal of native vegetation during its construction and maintenance (Gelbard \& Belnap, 2003), and changes in microclimatic conditions (Lembrechts et al., 2016). Roads can also facilitate non-native species introductions through the unintentional dispersal of seeds by vehicles (Ansong \& Pickering, 2013a). As a result, mountain roads often host a higher diversity of non-native species than the surrounding landscape, yet with a progressive decline in non-native diversity with increasing elevation (Alexander et al., 2011). With their often disruptive effects on native species communities and positive effects on non-natives, mountain roads can truly funnel non-native species into mountain environments. Nevertheless, invasion of non-native plant species away from mountain roads has been shown to be fairly limited up till now, among others due to the invasion resistance of undisturbed mountain vegetation (Lembrechts et al., 2016, McDougall et al., 2018). As a result, the set of traits needed for non-native plant species to follow roads to high elevations is different from the one needed to invade undisturbed mountain vegetation (McDougall et al., 2018).

Domestic livestock is an important disturbance factor and can promote the introduction and establishment of non-native species acting as seed dispersal agents and through trampling and grazing disturbance (Loydi \& Zalba, 2009; Ansong \& Pickering, 2013b). These disturbances can reduce biotic resistance due to consumption and trampling, potentially facilitating the introduction and expansion of disturbance-resistant species, including many non-native species, even in the highest protected areas in the Andes (Barros \& Pickering, 2014; Barros et al., 2020). As such, domestic livestock could potentially break the stalemate that limits plant invasion away from roadsides by reducing the resistance of the native vegetation and changing abiotic conditions in

83 favor of the roadside invaders. Additionally, "alien alliances" have commonly been observed, 84 where non-native herbivores promote non-native plants from their home range (Parker et al., 2006). 
Despite the recognized importance of environmental filtering on determining diversity of both natives and non-natives in mountains (McCain \& Grytnes, 2010), plant richness patterns of natives vs non-natives can differ substantially. A recent global synthesis along elevation gradients highlighted that distribution patterns are not ubiquitously consistent, with differences across regions and between plots at roadsides and undisturbed further plots (Haider et al., 2018). For the Andes region, explicit comparisons of plant species richness along elevation gradients have shown that the most common pattern for non-natives and natives was a hump shaped curve, both in the roadside and the interior vegetation (Haider et al., 2018). However, in plots at the roadsides a monotonically decrease for native richness was detected in temperate and tropical forests in Argentina and Colombia (Sandoya et al., 2017; Haider et al., 2018). Roads' effect on plant richness patterns in the Arid Andes of Argentina have not yet been explored. In this region, although native plant communities are characterized by species adapted to extreme climate conditions at high elevations, non-native species are still present, potentially driven by human disturbances and livestock (Barros \& Pickering, 2014; Barros et al., 2020).

Studying the combined effects of elevation, road disturbance and domestic livestock (and/or other non-native herbivores) on non-native plant distributions is thus critical to understand the interactive effects of these multiple disturbances, especially in regions where non-native herbivores are the main disturbance agents and a potential threat for plant invasions (Barros et al., 2014; Barros et al., 2020; Liedtke et al., 2020). Understanding how both disturbance types separately and together affect native communities and promote non-native plant invasions can assist in the development of mitigation actions as well as preventing further plant invasions in higher elevation ecosystems. It can also contribute to disentangle the importance of theories about environmental filtering (elevation), biotic resistance (herbivores) and soil disturbances (i.e. roads) and their interactions (Catford et al., 2009).

We here aim to understand the effects of disturbance related to road and non-native herbivores on plant diversity and invasions in the Arid Andes of Argentina. Specifically, we ask: (1) How non-native and native plant richness are affected by elevation, road disturbance and non-native herbivores? and 2) How non-native cover is affected by non-native herbivores in conjunction with road disturbance along elevation? For the first question, we hypothesized that native and non-native plant richness differ in their distribution pattern along elevation. We predict that many non-native 
115 species would be more restricted in elevation than native species due to a lower adaptation to local 116 environmental stress and the lowland provenance of most non-native species. We also expect that 117 distance to the road and herbivores, as a surrogate of disturbance, would also affect positively non118 native richness by increased bare soil and propagule pressure. Instead, native richness would be 119 negatively affected by these disturbance factors. For the second question, we expect that in 120 conjunction with environmental filtering imposed by elevation, distance to the road and the abundance of non-native herbivores would also be important factors explaining non-native cover.

\section{Methods:}

\section{Site description}

125 The study was conducted during summer 2016-2017 in the central zone of the Arid Andes of 126 Argentina, in the province of Mendoza from $-32 \mathrm{~S}$ to $-33{ }^{\circ} \mathrm{S}$, in the Cordillera Frontal and 127 Precordillera mountain ranges. We selected three mountain roads in protected areas: Villavicencio 128 Natural Reserve ( $\left.-32^{\circ} 31^{\prime} 31^{\prime \prime} \mathrm{S},-69^{\circ} 0^{\prime} 33^{\prime \prime} \mathrm{W}\right)$, Cordon del Plata Provincial Park (-33 0' 14" S, $\left.12969^{\circ} 17^{\prime} 50^{\prime \prime} \mathrm{W}\right)$, and Portillo-Piuquenes Natural Reserve (- $33^{\circ} 35^{\prime}$ 51" S, - 69 $0^{\prime} 33^{\prime \prime} \mathrm{W}$ ) (Fig. 1). The three roads were selected due to their similarity in flora and bioclimatic conditions, and for the wide elevational gradient that they cover, ranging from 1755 to $\sim 3919 \mathrm{~m}$ a.s.l. The gravel roads are open to traffic year-round, except at higher elevations (>2800 m a.s.l) during winter, where they can be temporarily closed due to snow cover.

Overall, the climate in the region is cold and dry, with strong variations in temperature and precipitation due to the broad elevational range and complex topography (Méndez, 2004). Low elevation areas are characterized by greater aridity and higher temperatures whereas higher elevation areas are cooler and wetter (Méndez, 2004). Precipitation mainly falls in autumn and winter, with precipitation totals ranging from $398 \mathrm{~mm}$ in Cordon del Plata to $120 \mathrm{~mm}$ in Villavicencio. On average, annual mean temperature ranges from $18^{\circ} \mathrm{C}$ in summer to $6^{\circ} \mathrm{C}$ in winter, with minimum temperatures during winter season below $0^{\circ} \mathrm{C}$ in these mountain roads (Cara et al., unpublished).

Soils in general are little developed and exhibit great spatial heterogeneity in depth and granulometric composition (Méndez, 2004; Méndez et al., 2006). Between 2400-3200 m a.s.1 soils 
144 are seasonally frozen, with permafrost occurring at higher elevations (Roig et al., 2007). The region forms part of the Andean biogeographic region (Morrone, 2006), and features a low (1700-2400 m a.s.1), intermediate (2500-3200) and high Andean vegetation belt (3200-4000 m a.s.1). The surveys were conducted mostly in steppe vegetation. The low and intermediate belts are characterized by shrublands (dominated by species such as Adesmia pinifolia, A. aegiceras, Colliguaja integerrima, Junellia juniperina) and herbaceous steppes (e.g. Pappostipa chrysophylla, Senecio subulatus, Acaena pinnatifida). The high Andean belt, where vegetation is more sparse, is dominated by cushion shrubs (e.g. Azorella monantha, A. subterranea) and some perennial herbaceous plants (e.g. S. trifidus, Poa holciformis) (Méndez et al., 2006, Kiesling et al., In Press). Previous floristic surveys have recorded over 500 native plant species in the region (Méndez et al., 2006; Méndez, 154 2009).

The provincial parks surrounding these mountain roads have limited past human use, and currently have very little human infrastructure except for a few mountain lodges. The main anthropogenic pressure results from regular touristic activities (sightseeing \& mountain sports, use of mountain lodges), and livestock grazing, including horses and cows (Barros \& Pickering, 2015). Other non-native wild grazers include the European hare (Lepus europaeus). The only large native grazing mammal is the camelid Lama guanicoe (guanaco) (Barros et al., 2014). Small and medium native rodents are also common, including species of caviomorphs such as the genus Galea, and several genera of sigmodontinae rodents such as Phyllotis, Euneomys, Abrothrix, among others (Novillo \& Ojeda, 2014)

Field sampling design and data collection

166 Standardized vegetation surveys following the survey design of the international Mountain Invasion 167 Research Network (MIREN, Haider et al., 2021) were performed along the 3 mountain roads 168 between spring 2016 and summer 2017. Each road was divided into 19 equally spaced elevation 169 bands along the gradient, resulting in 20 sample sites (hereafter called 'transects') per road. Each 170 transect had a "T" shape, consisting of three $50 \times 2 \mathrm{~m}$ plots, one along the edge of the road (plot 1) 171 and two others perpendicular to the road and leading away from the edge of the road (plot 2 and 3). 
We recorded the cover percentage of all angiosperms and gymnosperms in each plot in each

173

174

175

Plant species were identified, verified and finally stored in the Ruiz Leal Herbarium MERL (IADIZA, Argentina). Plant species identification and classification as native or non-native was based on the Darwinion Institute Flora database (www.floraargentina.edu.ar) following criteria by Zuloaga et al. (2008). Data was collected, compiled and standardized following the protocol of the MIREN consortium network and submitted to the MIREN database (Haider et al., 2021).

\section{Data Analyses}

All the analyses were performed in R (R Core, 2018). We analyzed if native and non-native plant richness changed with elevation, abundance of non-native herbivores, and distance to the road (PLOT $1=$ near road, PLOT 2=middle, PLOT $3=$ interior) by fitting mixed generalized linear models (GLMMs) assuming a Poisson (log link). We used the same explanatory variables to analyze nonnative cover assuming a binomial (logit link) distribution. For GLMMs, we used glmer() function in the lme4 package (Bates et al., 2015). In all the models, road was used as a random factor due to our field design for data collection. Continuous predictor variables were centered and scaled in order to standardize predictions so that the units of the regression coefficients are the same. In order to explore predictive importance of fixed and random effects on plant richness and cover we applied r.squaredGLMM() function from MuMIn package (Barton, 2020) and calculated marginal and conditional R2, this is the variance explained by fixed effects and the variance explained by both fixed and random effects, respectively (Nakagawa \& Schielzeth, 2013). To analyze the variance explained in GLMMs by unique or shared predictors we used partR2() function in partR2 package (Stoffel et al., 2021), this is calculated by monitoring the reduction in the fixed effect variance when a specified predictor is removed from the model, in relation to the total estimated variance. 
We analyzed plant richness separately for native and non-native species. In order to select the best relationship of richness and explanatory variables we compared models with or without quadratic elevation term, and models with and without the interaction of elevation and distance to the road, with and without the interaction between non-native herbivore abundance and distance to the road. We compared with Likelihood Ratio Tests the adjustment of models with and without interaction terms and to determine whether to keep or not interactive effects. Non-native plant cover was tested using as response variable the ratio of non-native cover: total plant cover to consider the expected low cover in harsh habitats in the high Andes, and to show the relative nonnative plant dominance in the total vegetation cover.

\section{Results:}

\section{(1) General results}

213 A total of 360 plant species were recorded along the 3 surveyed mountain roads, of which 41 (11\%) 214 were non-native. Both native and non-native plant species richness decreased with elevation (Table 215 1, Table S1, Fig. 1). In 88\% of the plots, at least one non-native plant species was detected. 216 Roadside plots hosted more than twice (2.33 times) the number of non-native species than the 217 interior plots. The most common non-native species were from temperate European origin (Figs. 218 S1, S2) and occupied an elevation range greater than $1000 \mathrm{~m}$, with some of them distributed 219 throughout the whole elevation gradient, including many common global invaders such as 220 Taraxacum officinale and Cerastium arvense.

We recorded a total of 1639 animal droppings, of which $81 \%$ were from non-native herbivores, mainly horses or mules (41\%), hares (20\%) and cows (17\%). Dung feces recorded from native herbivores were from guanacos $(11 \%)$ and micromammals $(8 \%)$. At two of the roads,

224 Manzano and Vallecitos, non-native herbivores (mainly cows and horses) were most abundant on 225 the intermediate plots while along the third road they were more abundant (mainly European hare) in the roadside. The abundance of native and non-native herbivores were negatively correlated (Spearman correlation, $S=1139500, p=0.02$, $r h o=-0.17$ ), hence only non-native herbivore counts were included in the following analyses. 
230 Both native and non-native plant species richness decreased with elevation, but road distance had 231 contrasting effects. Indeed, native species richness was on average $24 \%$ lower in the roadside than 232 in interior plots, while non-native richness was 50\% greater at roadsides. Non-native herbivores 233 were not important in explaining native and non-native species richness patterns (Table S1). In 234 GLMMs variance associated to the random factor (road identity) was more important for native 235 richness $(\sim 20 \%)$ than for non-native richness ( $\sim 4 \%$, see Table S1a, b). richness was best described by a hump-shaped pattern - with a peak in richness below the midelevation point at around 2000-2200 m a.s.1. (Fig. 2b). The interaction between distance to the road and elevation was important to describe native richness, but it was irrelevant for non-native richness. Increasing distance to the road resulted in a regular decline in non-native richness. However, native richness was almost constant along the elevational gradient near the roadside, but decreased linearly in vegetation far away from the road. When analyzing variance partitioning for fixed effects in GLMMs, elevation explained most of non-native richness variance (71\%) and distance to the road explained the rest of variance $(7 \%)$. For native richness, the interaction of elevation and distance to the road explained $38 \%$ of the variance.

247 Non-native plant cover was explained by the interactions of elevation with road distance, and non248 native herbivores with road distance. The variance associated to the random factor (road identity) 249 was very low (1\%). Elevation negatively affected non-native cover, yet it decreased smoother at 250 roadsides compared to interior plots (Table S2, Fig 3a). Overall, non-native cover was always 251 greater in roadsides than in interior plots $(\sim 12 \%$ higher, Fig. 3a). Non-native plant cover was 252 positively affected by the abundance of non-native herbivores, but only at middle and interior plots. 253 These plots showed an increase in non-native cover with increasing herbivory from around 10 to $25425 \%$ (Table S2, Fig. 3b). The variance was mainly explained by the interaction of elevation with 255 road distance (16\%), and a lower percentage (2\%) was explained by the interaction of road distance 256 with non-native herbivores.

\section{Discussion}


259 Our study confirms the findings from a growing body of literature showing the negative correlation 260 of non-native plant species with distance to the road and elevation (Alexander et al., 2011; Seipel et 261 al., 2012: Lembrechts et al., 2014; Haider et al., 2018), yet goes further up by incorporating the role 262 of non-native herbivores. Indeed, we found a positive effect of non-native herbivores on non-native 263 cover in plots away from the road, highlighting their role in facilitating plant invasions into natural 264 environments after their establishment in roadsides. These findings support previous research 265 stating the importance of interacting effects, such as combined disturbance and climate, determining 266 non-native plant invasions (Eschtruth \& Battles, 2009; Geppert et al., 2021). Roads also positively 267 affected non-native plant species richness, yet had a pervasive effect on native plants. These results 268 emphasize the important role of recurrent disturbance from roads in creating novel communities 269 dominated by non-native species in the extreme environment that characterize the high Andes.

\section{Environmental filtering and road disturbance}

271 Our results support previous research stating the importance of environmental filtering and 272 disturbance in determining species richness patterns and non-native cover along elevation gradients 273 (Alexander et al., 2011; Marini et al., 2012). The patterns found for non-native richness followed 274 the most common patterns observed globally, with a curved hump-shape for non-natives and a 275 linear decline with elevation for natives (Rahbek, 2005; McCain \& Grytnes, 2010). This also supports previous research conducted in tropical and temperature parts of the Andes (Sandoya et al., 2017; Haider et al., 2018). The hump-shaped curve observed for non-natives can be attributed to the climatic harshness experienced at the two ends of the gradient in the Arid Andes, including higher aridity at low elevations and low temperatures at high elevations. Other studies have also observed that aridity can be a limiting factor for non-native plants success at lower elevations (Arevalo et al. 2005; Haider et al., 2010; Jakobs et al., 2010). At higher elevations, the combination of lower propagule pressure and lower temperatures may have limited non-native plant establishment, allowing only a subset of lowland species to occur at these elevations (Haider et al., 2010; Alexander et al., 2011; Marini et al., 2013; Averett et al., 2016; Haider et al., 2018). For native species, there was a lack of association between native richness and elevation in the roadside plots, probably explained by recurrent disturbance from roads.

Roadside environments are characterized by high rates of disturbance and reduced competition, often favoring non-native plants with more acquisitive strategies over native plants 
289 with more conservative strategies (Spellerberg, 1998; Tecco et al., 2010; Haider et al., 2018). Non290 natives recorded in our study area were mainly ruderal plants with broad tolerance to recurrent 291 disturbance, also growing in other Andean regions and known as common global invaders (Fuentes292 Lillo \& Pauchard, 2019). Species were characterized by acquisitive strategies, mainly annuals or 293 short-lived perennials herbs, with high relative growth rate, high seed reproduction and high 294 Specific Leaf Area and low Leaf Dry Matter Content (Mazzolari et al., 2018). In contrast, native species, as observed in other mountain regions, tend to have more specific morphological and functional adaptations along the elevational gradient but with lower tolerance to recurrent human disturbance (Alexander et al., 2011). These are usually conservative species characterized by woody perennial forms, slow growth rate, reduced foliar area and high Leaf Dry Matter Content (Mazzolari et al., 2018). Hence the greater non-native richness at roadsides than interior plots, probably reflects the importance of their functional traits affecting their performance in roadside habitats. Other factors contributing to this pattern could be the higher propagule pressure on roads (Pauchard \& Alaback, 2004), that can be associated to seed dispersal by vehicles and imported soil materials that increases seed banks of non-native species at roadside edges (Gelbard \& Belnap, 2003; Ansong \& Pickering, 2013a)

\section{The role of non-native herbivory on non-native plant invasions}

306

In addition to the role of road disturbance, non-native herbivores can contribute to non-native plant success in mountains. We found that non-native herbivores, using dung abundance as a proxy, interacted with distance to the road, promoting plant invasions at further distances from the road edge. The impact of non-native herbivores on non-native plant invasion has been widely documented before (Maron \& Vilà, 2001; Parker \& Hay, 2005; Bobadilla et al., 2020; Geppert et al., 2021). Habitat modification due to trampling disturbance from domestic livestock, for example, can damage vegetation and expose soils favouring non-native plants more tolerant to disturbances (Barros et al., 2014; Farrell \& Fehmi, 2018); selective browsing and grazing on natives over nonnative species can indirectly promote their abundance (Mack, 1989; Parker et al., 2006). Other mechanisms that could be promoting non-native seed establishment beyond roads are seeds dispersal through the fur, cots and in the dung of animals, with many of the most frequent nonnatives recorded in our study (e.g. Taraxacum officinale, Verbascum thapsus, Rosa rubiginosa) known to be dispersed through livestock (Ansong \& Pickering, 2013b; Dacar et al., 2019). 
Other factors related to herbivory that could be contributing to non-native invasion, is the relatively high abundance of non-native herbivores compared to natives. Non-native herbivores

321 (mainly horses and cows) were the most dominant (81\%) and the only native grazing large 322 mammal, the guanaco, only accounted for $11 \%$ in our study area. Native and non-native herbivores 323 were also negatively correlated, with decreasing abundance of natives at greater abundance of non324 natives. The lower abundance of large native herbivores, the guanaco, could be due to several 325 reasons, including historical hunting pressure (Schroeder et al., 2013), differences in habitat 326 selection (Ovejero et al. 2011; Esteban et al., 2012) and animal avoidance of areas with human 327 pressure such as vehicle roads and settlements (Donadio \& Buskirk, 2006; Acebes et al., 2012). 328 Previous research has shown that alteration of herbivore communities, including loss or reduction of 329 native herbivores, can reduce biotic resistance to plant invasions because native herbivores tend to 330 limit the abundance of non-native plants while non-native herbivores tend to promote their 331 abundance (Parker et al., 2006). This is linked to the invasional meltdown hypothesis that associates 332 biological invasions with facilitation processes between non-native species (Relva et al., 2010; 333 Simberloff \& Von Holle, 1999). Unfortunately, the nature of our study does not allow us to identify the underlying 335 mechanisms that explain the positive relationship between non-native herbivory and plant 336 invasions. To better understand how herbivory, including native and non-native grazers, affect non337 native plant success in this system, further observational and experimental studies are required, 338 including assessing feeding preferences of non-natives vs. native grazers e.g. (Relva et al., 2010; 339 Morrison \& Hay, 2011; Averill et al., 2016) as well as disentangling the direct effects (seed 340 dispersal, trampling or consumption) and indirect effects (mutualistic interactions) of non-native 341 herbivores on native and introduced plants (Villalobos \& Zalba, 2010; Root et al., 2020).

\section{Conclusion}

344 Our study confirmed previous research assessing non-native and native plant distribution patterns 345 along elevation gradients, observing similar patterns in the Arid Andes as those found globally, with 346 largely declining richness of native and non-native plant species with increasing elevation. Our 347 results also highlighted the importance of recurrent disturbance from roads in harsh environments, 
348 such as the Arid Andes, with strong negative impacts on native species richness in roadsides 349 compared to areas further from the road, especially at lower elevations, yet significant increases in 350 non-native species richness. Additionally, we found a positive effect of non-native herbivores on 351 non-native plant success, highlighting their potential role as "alien allies" spreading non-native 352 plants away from the roadside. The fact that non-native herbivory can promote invasions further 353 from the roads and even at high elevations suggests that this disturbance potentially has a much broader area of impact than roadside disturbance itself. Consequently, implementing management guidelines aimed to minimize disturbance from roads and grazing of non-native herbivores is a key action for active restoration and to limit plant invasions in Andean mountains.

\section{ACKNOWLEDGMENTS}

This study is part of the research carried out by the Mountain Invasion Research Network (MIREN; www.mountaininvasions.org). The aim of MIREN is to understand the effects of global change on species' distributions and biodiversity in mountainous areas. We perform observational and experimental studies along elevation gradients to evaluate and quantify the processes and mechanisms that are shaping mountain plant communities at regional and global scales. This research was funded by SIP UNCUYO M022, RUFFORD Small Grant and Fundación Villavivencio. We appreciate the support provided in the field by Park rangers and land owners.

\section{DECLARATIONS}

Conflict of interest The authors declare no conflict of interest.

Authors' contributions: V. Aschero, A.A. Barros, A. Pauchard and J.J. Lembrechts designed the study; V.Aschero, A. Mazzolari, A.A. Barros, M.A. Alvarez, F. Cuevas, A. Novillo, M. Pérez Sosa, and L. Bonjour carried out the field work; L. Bonjour, M.A. Alvarez, V. Aschero, and A.A. Barros, identified the plant species; V.Aschero, A. A. Barros, analyzed the data and wrote the first draft of the article. All authors contributed to manuscript writing, editing the discussion, and critical review of the article.

\section{Data availability}


376 Data collected according to the MIREN road survey protocol. Details about data-sharing agreement 377 is available on the network's website (www.mountaininvasions.org) and provided if requested to 378 VA vaschero@mendoza-conicet.gob.ar or AB anaagustinabarros@gmail.com.

\section{TABLES AND FIGURE CAPTIONS}

Table 1. Average number of species and percentage of vegetation cover (mean \pm standard error) estimated at different elevations (m a.s.l) per plot $\left(100 \mathrm{~m}^{2}\right)$. The data were collected following the international MIREN standard T-transect vegetation survey.

\begin{tabular}{lccrrr}
\hline Elevation & $\begin{array}{r}\text { Range m a.s.1 } \\
(\min -m a x)\end{array}$ & $\begin{array}{r}\text { Native } \\
\text { richness }\end{array}$ & $\begin{array}{r}\text { Non-native } \\
\text { richness }\end{array}$ & $\begin{array}{r}\text { Native } \\
\text { cover (\%) }\end{array}$ & $\begin{array}{r}\text { Non-native } \\
\text { cover (\%) }\end{array}$ \\
\hline Low $(\mathrm{n}=21)$ & $1754-2557$ & $20 \pm 5$ & $5 \pm 2$ & $51.5 \pm 31.8$ & $23.0 \pm 22.7$ \\
\hline Middle $(\mathrm{n}=21)$ & $2635-3272$ & $19 \pm 6$ & $3 \pm 2$ & $58.7 \pm 33.3$ & $15.3 \pm 16.3$ \\
\hline High $(\mathrm{n}=18)$ & $3300-3919$ & $16 \pm 7$ & $1 \pm 1$ & $50.7 \pm 32.3$ & $5.8 \pm 8.3$
\end{tabular}

FIGURE CAPTIONS

Fig. 1 Map of the study area located in the Arid Central Andes in Argentina (-33 $0^{\prime} 14^{\prime \prime} \mathrm{S}, 69^{\circ} 17^{\prime}$ 50 " W). Red polygons represent protected areas and black lines the roads surveyed.

Fig. 2 Predicted (lines) and observed (points) of (a) native and (b) non-native species richness along the elevation gradient and at different distances from vehicular roads (Plot 1=roadside, $2=$ middle and $3=$ interior) in the Arid Central Andes of Argentina. Because the explanatory variable had different range, elevation was standardized using the scale() function in $\mathrm{R}$.

Fig. 3 Non-native plant cover response predicted by binomial GLMMs using (a) elevation and (b) non-native herbivores as explanatory variables (color lines; Plot 1=roadside, $2=$ middle and $3943=$ interior). 
Non-native plants in the Arid Andes

\section{References}

Acebes, P., Traba, J., \& Malo, J. (2012). Co-occurrence and potential for competition between wild and domestic large herbivores in a South American desert. Journal of Arid Environments, 77, 39-44.

Alexander, J. M., Kueffer, C., Daehler, C. C., Edwards, P. J., Pauchard, A., Seipel, T., . . Jakobs, G. (2011). Assembly of nonnative floras along elevational gradients explained by directional ecological filtering. Proceedings of the National Academy of Sciences, 108(2), 656-661.

Alexander, J. M., Lembrechts, J. J., Cavieres, L. A., Daehler, C., Haider, S., Kueffer, C., . . Pauchard, A. J. A. B. (2016). Plant invasions into mountains and alpine ecosystems: current status and future challenges. Alpine Botany, 126(2), 89-103.

Alexander, J. M., Naylor, B., Poll, M., Edwards, P. J., \& Dietz, H. (2009). Plant invasions along mountain roads: the altitudinal amplitude of alien Asteraceae forbs in their native and introduced ranges. Ecography, 32(2), 334-344.

Ansong, M., \& Pickering, C. (2013a). Are weeds hitchhiking a ride on your car? A systematic review of seed dispersal on cars. PLoS ONE, 8(11), e80275.

Ansong, M., \& Pickering, C. (2013b). A global review of weeds that can germinate from horse dung. Ecological Management and Restoration, 14(3), 216-223.

Arévalo, J. R., Delgado, J. D., Otto, R., Naranjo, A., Salas, M., \& Fernández-Palacios, J. M. (2005). Distribution of alien vs. native plant species in roadside communities along an altitudinal gradient in Tenerife and Gran Canaria (Canary Islands). Perspectives in Plant Ecology, Evolution and Systematics, 7(3), 185-202.

Averill, K. M., Mortensen, D. A., Smithwick, E. A., \& Post, E. (2016). Deer feeding selectivity for invasive plants. Biological Invasions, 18(5), 1247-1263.

Badano, E. I., Villarroel, E., Bustamante, R. O., Marquet, P. A., \& Cavieres, L. A. (2007). Ecosystem engineering facilitates invasions by exotic plants in high-Andean ecosystems. Journal of Ecology, 95(4), 682-688.

Barros, A., Aschero, V., Mazzolari, A., Cavieres, L. A., \& Pickering, C. M. (2020). Going off trails: How dispersed visitor use affects alpine vegetation. Journal of Environmental Management, 267, 110546. doi:https://doi.org/10.1016/i.jenvman.2020.110546

Barros, A., Pickering, C., \& Renison, D. (2014). Short-term effects of pack animal grazing exclusion from Andean alpine meadows. Arctic, Antarctic, and Alpine Research, 46(2), 41-51.

Barros, A., \& Pickering, C. M. (2014). Non-native plant invasion in relation to tourism use of Aconcagua Park, Argentina, the highest protected area in the Southern Hemisphere. Mountain Research and Development, 34(1), 13-26.

Barros, A., \& Pickering, C. M. (2015). Impacts of experimental trampling by hikers and pack animals on a high-altitude alpine sedge meadow in the Andes. Plant Ecology and Diversity, 8(2), 265-276. doi:10.1080/17550874.2014.893592

Barton, K. (2020). MuMIn: Multi-Model Inference. R package version 1.43.17. https://CRAN.Rproject.org/package=MuMIn

Bates D, Maechler M, Bolker B, Walker S (2015). Fitting Linear Mixed-Effects Models Using lme4. Journal of Statistical Software, 67(1), 1-48 doi:10.18637/jss.v067.i01.

Bobadilla, S. Y., Marchetta, A., Dacar, M. A., Ojeda, R. A., \& Cuevas, M. F. (2020). Food habits of European rabbit and its role as seed dispersal of two Mosqueta roses: Facilitation among non-native species in a semiarid protected area of Argentina?. Biological Invasions, 1-7.

Burnham, K., \& Anderson, D. (2002). Model Section and Multimodel Inferences: A Practical-theoretic Approach (2nd edn). New York City: Springer-Verlag.

Catford, J. A., Jansson, R., \& Nilsson, C. (2009). Reducing redundancy in invasion ecology by integrating hypotheses into a single theoretical framework. Diversity \& Distributions, 15(1), 22-40. 
Cavieres, L. A., Badano, E. I., Sierra-Almeida, A., \& Molina-Montenegro, M. A. (2007). Microclimatic modifications of cushion plants and their consequences for seedling survival of native and nonnative herbaceous species in the high Andes of central Chile. Arctic, Antarctic, and Alpine Research, 39(2), 229-236.

Cavieres, L. A., Quiroz, C. L., Molina-Montenegro, M. A., Muñoz, A. A., \& Pauchard, A. (2005). Nurse effect of the native cushion plant Azorella monantha on the invasive non-native Taraxacum officinale in the high-Andes of central Chile. Perspectives in Plant Ecology, Evolution and Systematics, 7(3), 217-226. doi:http://dx.doi.org/10.1016/i.ppees.2005.09.002

Dacar, M. A., Dalmasso, A. D., Bobadilla, S. Y., \& Cuevas, M. F. (2019). Rol del ganado doméstico en el establecimiento de la especie invasora rosa mosqueta (Rosa rubiginosa l.) En los Andes Áridos, Argentina. Mastozoologia Neotropical, 26(2), 331-340.

De Villalobos, A. E., \& Schwerdt, L. (2018). Feral horses and alien plants: effects on the structure and function of the Pampean Mountain grasslands (Argentina). Ecoscience, 25(1), 49-60.

Donadio, E., \& Buskirk, S. W. (2006). Flight behavior in guanacos and vicuñas in areas with and without poaching in western Argentina. Biological Conservation, 127(2), 139-145. doi:10.1016/j.biocon.2005.08.004

Eschtruth, A. K., \& Battles, J. J. (2009). Assessing the relative importance of disturbance, herbivory, diversity, and propagule pressure in exotic plant invasion. Ecological Monographs, 79(2), 265280.

Esteban, R. S., Pastur, G. M., Lencinas, M. V., \& Borrelli, L. (2012). Differential forage use between large native and domestic herbivores in Southern Patagonian Nothofagus forests. Agroforestry Systems, 85(3), 397-409.

Farrell, H. L., \& Fehmi, J. S. (2018). Seeding alters plant community trajectory: Impacts of seeding, grazing and trampling on semi-arid re-vegetation. Applied Vegetation Science, 21(2), 240-249.

Fuentes-Lillo, E., \& Pauchard, A. (2019). Invasiones en montañas: ¿ Cuánto hemos avanzado en los últimos 10 años y cuáles son los desafíos para los ecosistemas de los Andes? Gayana. Botánica, 76(2), 141-155.

Geppert, C., Boscutti, F., La Bella, G., De Marchi, V., Corcos, D., Filippi, A., \& Marini, L. (2021). Contrasting response of native and non-native plants to disturbance and herbivory in mountain environments. Journal of Biogeography.

Haider, S., Kueffer, C., Bruelheide, H., Seipel, T., Alexander, J. M., Rew, L. J., . . Biogeography. (2018). Mountain roads and non-native species modify elevational patterns of plant diversity. Global Ecology and Biogeography, Arévalo, J. R., Delgado, J. D., Otto, R., Naranjo, A., Salas, M., \& Fernández-Palacios, J. M. (2005). Distribution of alien vs. native plant species in roadside communities along an altitudinal gradient in Tenerife and Gran Canaria (Canary Islands). Perspectives in Plant Ecology, Evolution and Systematics, 7(3), 185-202. 27(6), 667-678.

Jakobs, G., Kueffer, C., \& Daehler, C. C. (2010). Introduced weed richness across altitudinal gradients in Hawai'i: humps, humans and water-energy dynamics. Biological invasions, 12(12), 4019-4031.

Jesson, L., Kelly, D., \& Sparrow, A. (2000). The importance of dispersal, disturbance, and competition for exotic plant invasions in Arthur's Pass National Park, New Zealand. New Zealand Journal of Botany, 38(3), 451-468.

Jiménez, A., Pauchard, A., Cavieres, L. A., Marticorena, A., \& Bustamante, R. O. (2008). Do climatically similar regions contain similar alien floras? A comparison between the mediterranean areas of central Chile and California. Journal of Biogeography, 35(4), 614-624.

Kiesling, R., Bonjour, L., \& Monaco, G. (2021). Plantas de los Andes Centrales de la Argentina. Cordoba: Ecoval. Córdoba.

Kueffer, C., Daehler, C., Dietz, H., McDougall, K., Parks, C., Pauchard, A., \& Rew, L. (2014). The Mountain Invasion Research Network (MIREN). Linking local and global scales for addressing an 
ecological consequence of global change. GAIA-Ecological Perspectives for Science and Society, 23(3), 263-265.

Lembrechts, J. J., Alexander, J. M., Cavieres, L. A., Haider, S., Lenoir, J., Kueffer, C., . . Pauchard, A. (2016). Mountain roads shift native and non-native plant species' ranges. Ecography.

Lembrechts, J. J., Milbau, A., \& Nijs, I. J. P. O. (2014). Alien roadside species more easily invade alpine than lowland plant communities in a subarctic mountain ecosystem. PLoS one 9(2), e89664.

Liedtke, R., Barros, A., Essl, F., Lembrechts, J. J., Wedegärtner, R. E. M., Pauchard, A., \& Dullinger, S. (2020). Hiking trails as conduits for the spread of non-native species in mountain areas. Biological Invasions, 22(3), 1121-1134. doi:10.1007/s10530-019-02165-9

Loydi, A., \& Zalba, S. (2009). Feral horses dung piles as potential invasion windows for alien plant species in natural grasslands. Plant Ecology, 201(2), 471-480. doi:10.1007/s11258-008-9468-0

Mack, R. N. (1989). Temperate grasslands vulnerable to plant invasions: characteristics and consequences. Biological invasions: a global perspective, 22, 155-179.

Marini, L., Battisti, A., Bona, E., Federici, G., Martini, F., Pautasso, M., \& Hulme, P. E. (2012). Alien and native plant life-forms respond differently to human and climate pressures. Global Ecology and Biogeography, 21(5), 534-544.

Maron, J. L., \& Vilà, M. (2001). When do herbivores affect plant invasion? Evidence for the natural enemies and biotic resistance hypotheses. Oikos, 95(3), 361-373.

Mazzolari, A., Aschero, V., Barros, A., Bonjour, L., Cruz Perez, M., \& Tecco, P. A. (2018). Plantas exóticas en los Andes Centrales de Mendoza: caracterización funcional y efecto de los caminos vehiculares en su distribución altitudinal. Paper presented at the XXVIII Reunión Argentina de Ecología Mar del Plata.

McCain, C. M., \& Grytnes, J. A. (2010). Elevational gradients in species richness. Chichester: John Wiley \& Sons.

McDougall, K. L., Alexander, J. M., Haider, S., Pauchard, A., Walsh, N. G., \& Kueffer, C. (2011). Alien flora of mountains: global comparisons for the development of local preventive measures against plant invasions. Diversity and Distributions, 17(1), 103-111.

McDougall, K. L., Morgan, J. W., Walsh, N. G., \& Williams, R. J. (2005). Plant invasions in treeless vegetation of the Australian Alps. Perspectives in Plant Ecology, Evolution and Systematics, 7(3), $159-171$.

Méndez, E. (2004). La vegetación de los Altos Andes I. Pisos de vegetación del flanco oriental del Cordón del Plata (Mendoza, Argentina). Boletin de la Sociedad Argentina de Botanica, 39, 227 253.

Méndez, E. (2009). Biodiversidad de la Flora del flanco oriental del Cordón del Plata (Luján de Cuyo, Mendoza, Argentina). Catálogo Florístico. Boletin de la Sociedad Argentina de Botanica, '44, 75102.

Méndez, E., Martinez Carretero, E., \& Peralta, I. (2006). La vegetación del Parque Provincial Aconcagua (Altos Andes Centrales de Mendoza, Argentina). Boletín de la Sociedad Argentina de Botánica, 41, 41-49.

Morrison, W. E., \& Hay, M. E. (2011). Herbivore Preference for Native vs. Exotic Plants: Generalist Herbivores from Multiple Continents Prefer Exotic Plants That Are Evolutionarily Naïve. PLoS ONE, 6(3), e17227. doi:10.1371/journal.pone.0017227

Morrone, J. J. (2006). Biogeographic areas and transition zones of Latin America and the Caribbean islands based on panbiogeographic and cladistic analyses of the entomofauna. Annu. Rev. Entomol., 51, 467-494.

Müllerová, J., Vítková, M., \& Vítek, O. (2011). The impacts of road and walking trails upon adjacent vegetation: Effects of road building materials on species composition in a nutrient poor environment. Science of The Total Environment, 409(19), 3839-3849. 
Nakagawa, Shinichi, and Holger Schielzeth. (2013). A general and simple method for obtaining R2 from generalized linear mixed-effects models. Methods in Ecology and Evolution, 4 (2), 133-142.

Novillo, A., \& Ojeda, R. A. (2014). Elevation patterns in rodent diversity in the dry Andes: disentangling the role of environmental factors. Journal of Mammalogy, 95(1), 99-107.

Ovejero, R. J., Acebes, P., Malo, J. E., Traba, J., Torres, M. E. M., \& Borghi, C. E. (2011). Lack of feral livestock interference with native guanaco during the dry season in a South American desert. European journal of wildlife research, 57(5), 1007-1015.

Parker, J. D., Burkepile, D. E., \& Hay, M. E. (2006). Opposing effects of native and exotic herbivores on plant invasions. Science, 311(5766), 1459-1461.

Parker, J. D., \& Hay, M. E. (2005). Biotic resistance to plant invasions? Native herbivores prefer nonnative plants. Ecology Letters, 8(9), 959-967. doi:10.1111/j.1461-0248.2005.00799.x

Parks, C. G., Radosevich, S. R., Endress, B. A., Naylor, B. J., Anzinger, D., Rew, L. J., . . . Dwire, K. A. (2005). Natural and land-use history of the Northwest mountain ecoregions (USA) in relation to patterns of plant invasions. Perspectives in Plant Ecology, Evolution and Systematics, 7(3), 137158.

Pauchard, A., \& Alaback, P. B. (2004). Influence of elevation, land use, and landscape context on patterns of alien plant invasions along roadsides in protected areas of South Central Chile. Conservation Biology, 18(1), 238-248.

Pauchard, A., Kueffer, C., Dietz, H., Daehler, C. C., Alexander, J., Edwards, P. J., . . Haider, S. (2009). Ain't no mountain high enough: plant invasions reaching new elevations. Frontiers in Ecology and the Environment, 7(9), 479-486.

Petitpierre, B., McDougall, K., Seipel, T., Broennimann, O., Guisan, A., \& Kueffer, C. (2016). Will climate change increase the risk of plant invasions into mountains? Ecological Applications, 26(2), 530544.

R Core, T. (2018). R: A language and environment for statistical computing. R Foundation for Statistical Computing, Vienna, Austria. URL https://www.R-project.org.

Rahbek, C. (2005). The role of spatial scale and the perception of large-scale species-richness patterns. Ecology Letters, 8(2), 224-239.

Relva, M. A., Nunez, M. A., \& Simberloff, D. (2010). Introduced deer reduce native plant cover and facilitate invasion of non-native tree species: evidence for invasional meltdown. Biological Invasions, 12(2), 303-311.

Roig, F. A., Abraham, E. M., \& Méndez, E. (2007). Vegetation belts, cold and soil freezing in the Central Andes of Mendoza, Argentina. Phytocoenologia, 37(1), 99-113.

Root, H. T., Miller, J. E., \& Rosentreter, R. (2020). Grazing disturbance promotes exotic annual grasses by degrading soil biocrust communities. Ecological Applications, 30(1), e02016.

Sandoya, V., Pauchard, A., \& Cavieres, L. A. (2017). Natives and non-natives plants show different responses to elevation and disturbance on the tropical high Andes of Ecuador. Ecology and evolution, 7(19), 7909-7919.

Schroeder, N., Ovejero, R., Moreno, P. G., Gregorio, P., Taraborelli, P., Matteucci, S. D., \& Carmanchahi, P. D. (2013). Including species interactions in resource selection of guanacos and livestock in Northern Patagonia. Journal of Zoology, 291(3), 213-225.

Seipel, T., Kueffer, C., Rew, L. J., Daehler, C. C., Pauchard, A., Naylor, B. J., . . A Arevalo, J. R. (2012). Processes at multiple scales affect richness and similarity of non-native plant species in mountains around the world. Global Ecology and Biogeography, 21(2), 236-246.

Simberloff, D., \& Von Holle, B. (1999). Positive interactions of nonindigenous species: invasional meltdown? Biological Invasions, 1(1), 21-32.

Spellerberg, I. (1998). Ecological effects of roads and traffic: a literature review. Global Ecology \& Biogeography Letters, 7(5), 317-333. 
587 Stoffel, M. A., Nakagawa, S., \& Schielzeth, H. (2021). partR2: Partitioning R2 in generalized linear mixed models. PeerJ 9:e11414 https://doi.org/10.7717/peerj.11414

Tecco, P. A., Díaz, S., Cabido, M., \& Urcelay, C. (2010). Functional traits of alien plants across contrasting climatic and land-use regimes: do aliens join the locals or try harder than them? Journal of Ecology, 98(1), 17-27.

Villalobos, A. E., \& Zalba, S. M. (2010). Continuos feral horse grazing and grazing exclusion in mountain pampean grasslands in Argentina. Acta Oecologia, 36, 514-519.

Zuloaga, F. O., \& Belgrano, M. J. (2008). Catálogo de las plantas vasculares del Cono Sur: Pteridophyta, gymnospermae y monocotyledoneae. Volumen 1. Missouri: Missouri Botanical Garden.

597 


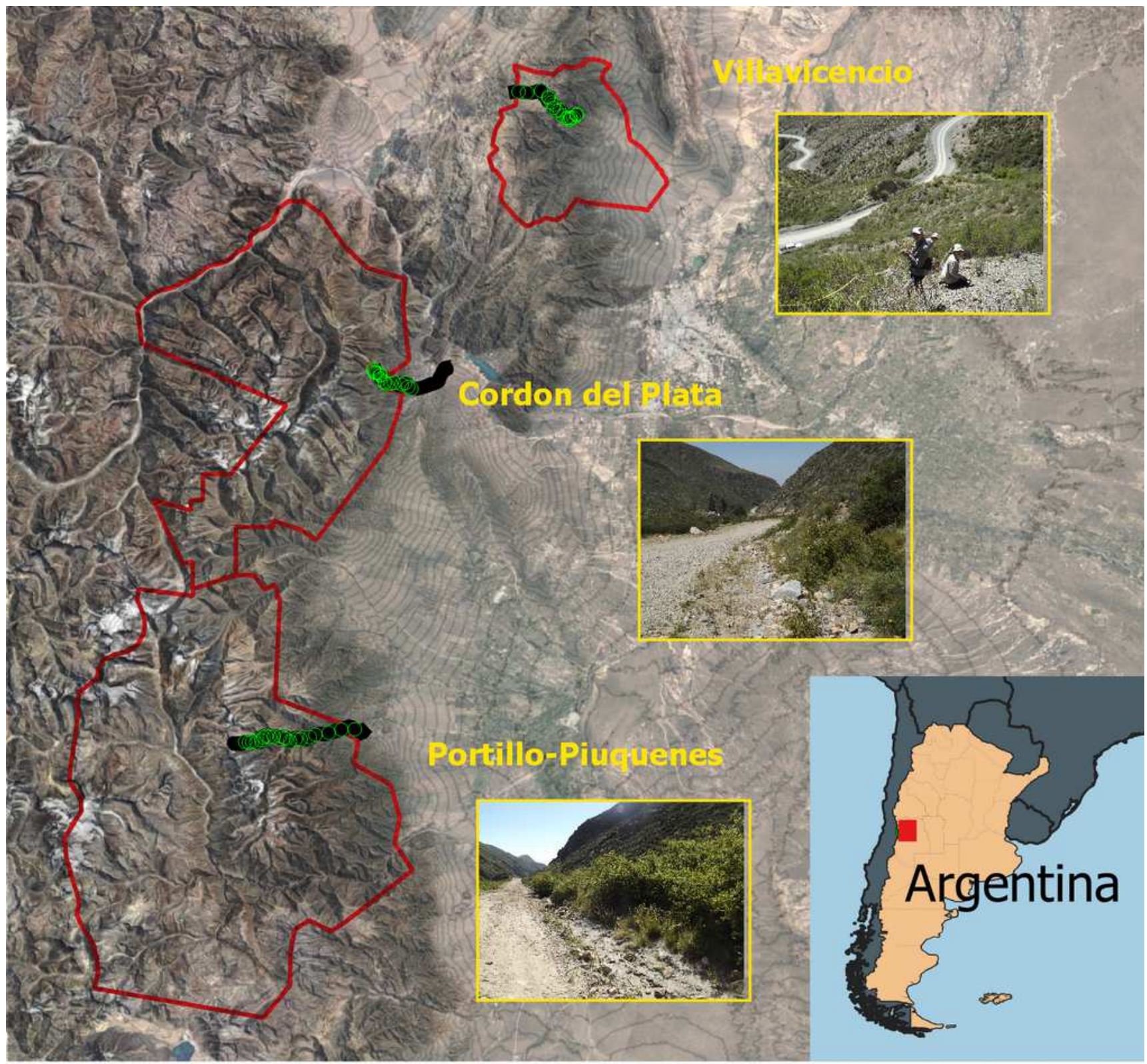

\section{MIREN sites}

Mountain roads

Protected areas

Contour lines (50m)



Coordinate system

CRS EPSG:32719 - WGS 84 / UTM zone 19S - Projected

\section{Figure 1}

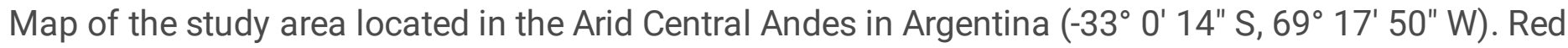
polygons represent protected areas and black lines the roads surveyed. 


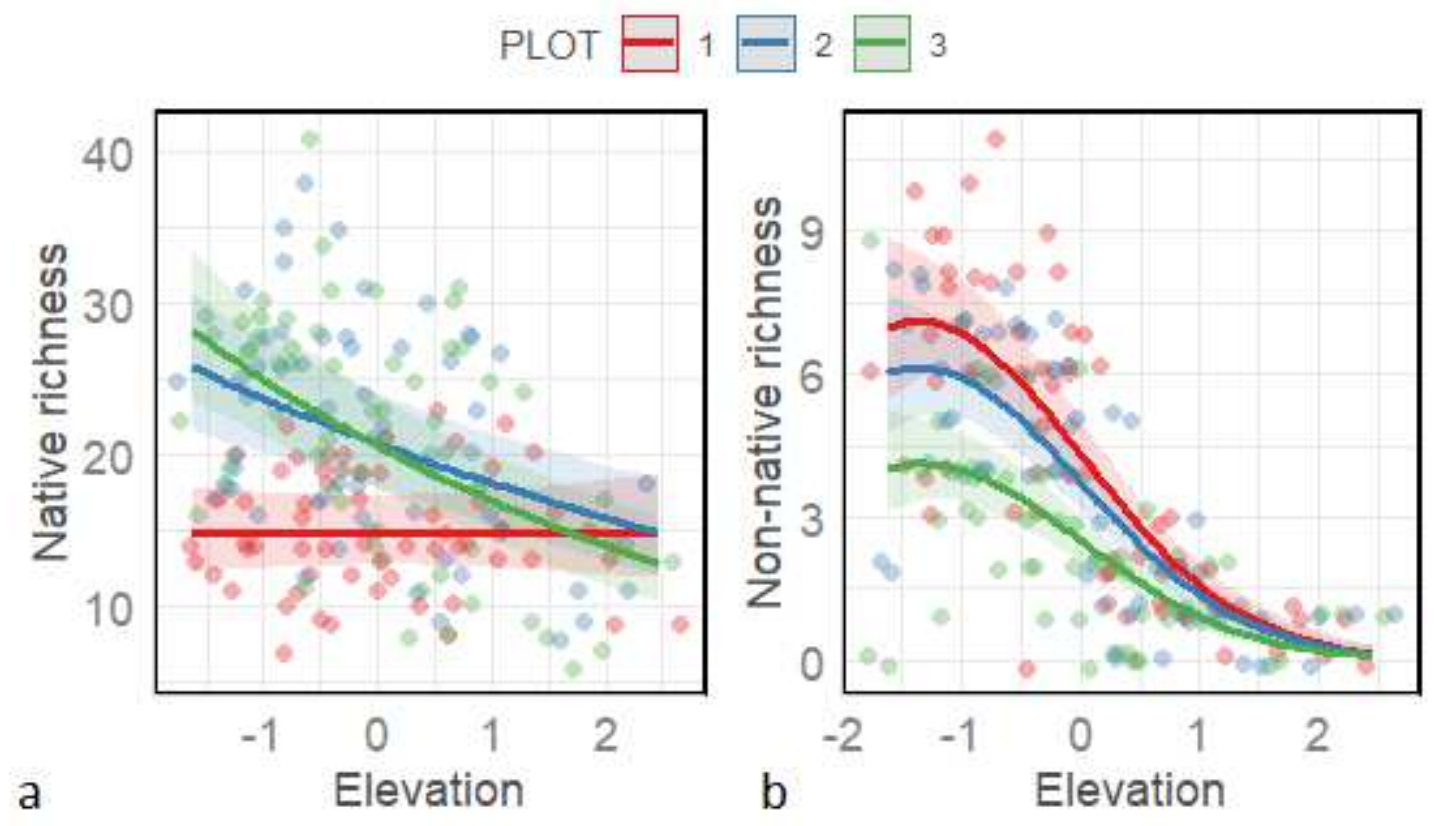

Figure 2

Predicted (lines) and observed (points) of (a) native and (b) non-native species richness along the elevation gradient and at different distances from vehicular roads (Plot $1=$ roadside, $2=$ middle and $3=$ interior) in the Arid Central Andes of Argentina. Because the explanatory variable had different range, elevation was standardized using the scale() function in R.

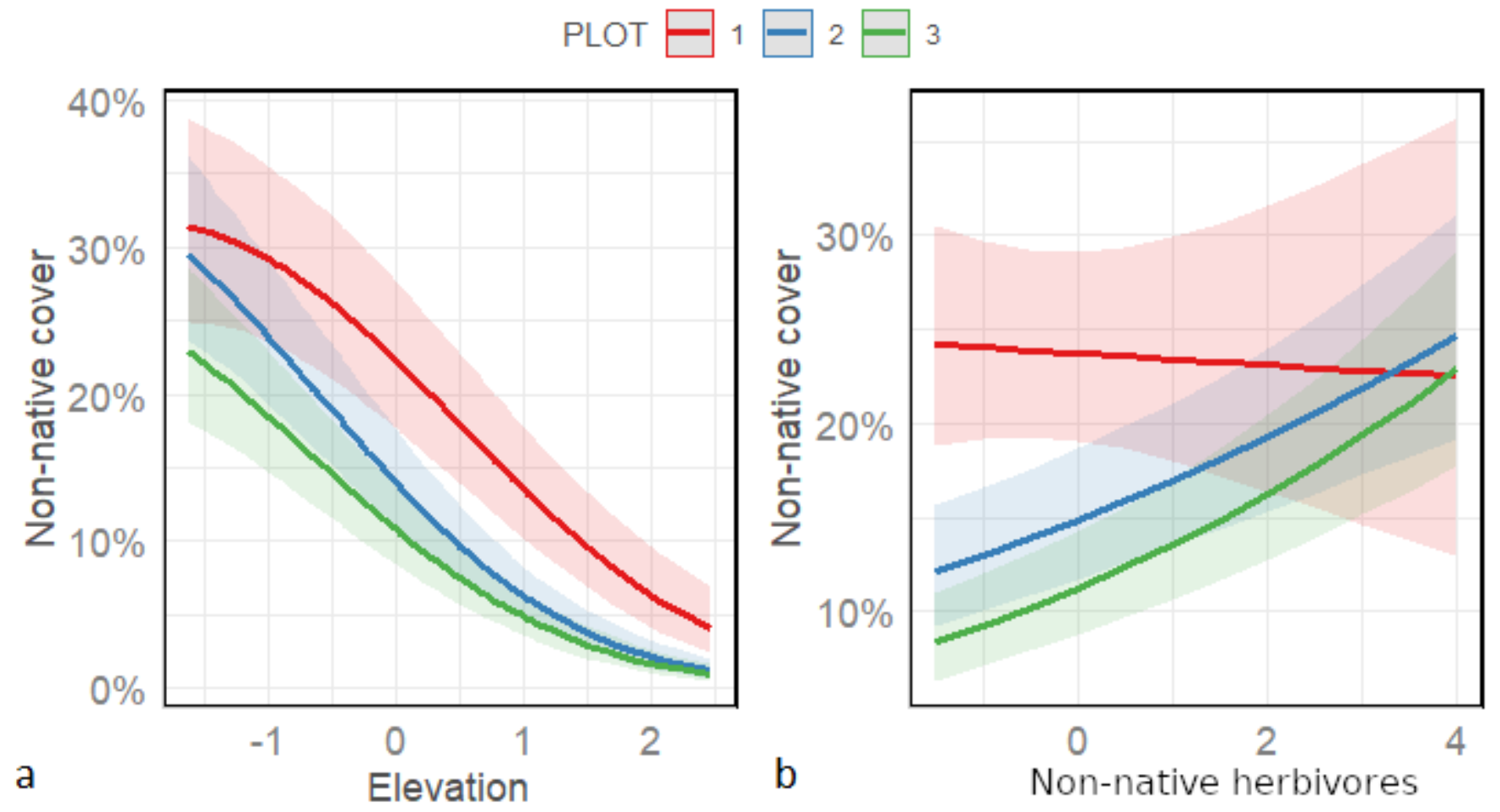

Figure 3 
Non-native plant cover response predicted by binomial GLMMs using (a) elevation and (b) non-native herbivores as explanatory variables (color lines; Plot $1=$ roadside, $2=$ middle and $3=$ interior).

\section{Supplementary Files}

This is a list of supplementary files associated with this preprint. Click to download.

- SuppMatAscheroBarrosetal.pdf 